\title{
Evaluation on the Energy Efficiency for Chinese cities
}

\author{
Han Siwei ${ }^{1}$, Wang Linyu ${ }^{12}$, Guo Lei ${ }^{12}$, Liu Shuai ${ }^{3}$, Song Guojun ${ }^{4}$, Song Tianyi ${ }^{5}$ \\ 1. state grid(Suzhou) City and energy research institute 215163, \\ 2. state grid energy research institute, 102209 ; \\ 3. Administration and Management Institute of Ministry of Agriculture and Rural Affairs, PRC,102208; \\ 4. Renmin University of China,100872; \\ 5. Beijing EnDigishare Environmental Techniques Research Institute Coperation, 100872;
}

\begin{abstract}
This study fully considers the incomparable factors in city's energy efficiency assessment, and proposes a framework for city's energy efficiency assessment based on classification. In the process of classifying cities, the SVM method is used to establish a quantitative relationship model between relevant factors and city's energy consumption. Based on the model, the objective energy demand of the city is calculated, and the city is classified according to the level of objective energy demand. By comparing the actual energy consumption of the city with the objective energy demand, we can eliminate the interference of the incomparable factors on the city's energy efficiency assessment.
\end{abstract}

\section{Introduction}

At present, China has been evaluating and managing the city's energy efficiency through the energy-saving targetoriented responsibility system. The system take the energy consumption per unit of GDP as the main assessment indicator. Primarily, the target of reducing energy consumption per unit of GDP during the period of " 13 th Five-Year Plan" is a 15\% reduction from the 2015 level, and require each city government to implement it. Those who fail to meet this target will held accountable through a "one-vote veto" mechanism. This study believes that there are many problems in this system, which include: firstly, the simply use of energy consumption per unit of GDP as the main indicator to rank all the cities in China ignores the diversity and comparability in this issue. Secondly, all cities set almost the same energy-saving targets, not considering that different cities have their own potentials. Thirdly, under the "one-vote veto" mechanism, city governments may have the motivation to achieve energy conservation at all costs, including improper adjustment of industrial structure and the use of excessively high-cost technologies.

In response to the problems mentioned above, China need to adopt a more effective and equitable strategy to improve the energy efficiency in cities. The literature has done some research on this issue. In the book "New renewable energy resources: a guide to the future" published by the World Energy Commission in 1994, "energy efficiency" is defined as: "reducing energy input to provide equal energy services"[ 1] . The energy efficiency indicators most often used include energy consumption per capita, energy consumption per unit of GDP, household energy consumption per capita, etc. According to the number of indicators used to in assessment, the method can be divided into singleindicator and multi-indicator method ${ }^{[2][3][4]}$. Further more, literature analyzed the relationship between energy efficiency and city's population, economic and social conditions, including the city's GDP, industrial structure, geography location, natural resources, energy price, technology level, investment, government regulation, etc ${ }^{[5][6][7]}$, which lead to our attention on the diversity and comparability of cities in the process of energy efficiency assessment. ${ }^{[8][9][10]}$

In this study, the single-indicator strategy is adopted, and the energy consumption per capita is selected as the assessment indicator, which can better reflect the overall energy consumption of a city. Generally, this study focuses on the comparability among cities while conducting the energy efficiency assessment, taking into account the impact of uncontrollable factors such as geographic location and climatic conditions, so as to establish a more equitable way of assessing energy efficiency of cities.

\section{Framework \& Methodology}

\subsection{Framework}

First, we identify uncontrollable factors that have impact on city's energy efficiency. Uncontrollable factors refer to the objective reasons for cities' energy efficiency differences. For instance, the need for winter heating in northern cities may lead to a higher energy demand in these cities, and it is obviously unfair to define these northern cites as less energy-efficient because of that. Apart from the heating reason, the city's population, urbanization rate, industrial structure can all have some impact on the city's energy demand, and are all

\footnotetext{
* Corresponding author: Song Guojun: songguojun@,ruc.edu.cn
} 
uncontrollable to some extent.

To this end, we need to propose a way to exclude these uncontrollable factors from city's energy efficiency assessment. This study uses a quantitative approach to classify cities, which requires us to accurately quantify the impact of objective uncontrollable factors on city's energy efficiency, and to classify cities based on this impact. Here, we define the concept of objective energy demand, which refers to the impact of objective uncontrollable factors on urban energy efficiency without considering the subjective efforts of the city. Specifically, we use Support Vector Machine(SVM) to establish the quantitative relationship between city's energy consumption and objective uncontrollable factors: city's energy consumption as the explained variable, objective uncontrollable factors as the explanatory variable. Training samples are selected randomly. After that, the model is applied to all samples, and the obtained city's energy consumption output is the objective energy consumption demand we want to calculate.

When actually using this model to evaluate cities, we need to compare the actual energy consumption of the city with the objective energy demand calculated based on the model, as a basis for judging the advanced level of city's energy efficiency. In the model, we did not include subjective controllable factors, that is, we did not consider the subjective efforts of the city. Therefore, when we use this model, we actually erase the subjective efforts of the city. All cities are assumed to be at the same level in their subjective efforts. In this way, if the actual energy consumption of a city is lower than the objective energy demand of the city, then the city is considered to be superior to the average of all cities in terms of subjective efforts, and vice versa.

\subsection{Methodology}

This study uses the SVM method to establish the relationship between city's energy efficiency and influencing factors. SVM method is a new general learning method. SVM has very good generalization ability in nonlinear classification, function approximation, pattern recognition and other applications. It has the advantages of strong generalization ability, convergence to global optimal, and dimension insensitivity. Based on this method, we establish the model, which has a structure as follows:

$$
Y=\sum_{i}^{n}-\alpha_{i} K\left(x_{i}, x_{j}\right)+b
$$

In the model structure, the kernel function uses the RBF kernel function, and the model form is:

$$
\mathrm{K}\left(\mathrm{x}_{\mathrm{i}}, \mathrm{x}_{\mathrm{j}}\right)=\exp \left(-\gamma\left\|\mathrm{x}_{\mathrm{i}}-\mathrm{x}_{\mathrm{j}}\right\|^{2}\right)
$$

The RBF kernel function is the Euclidean distance of the input variable matrix, $\gamma$ is given after trial. $x_{i}$ and $\mathrm{x}_{\mathrm{j}}$ are the support vectors, that is, the input variable of the training set used to construct the decision model, $\mathrm{x}_{\mathrm{i}}$ represents the input variable of the $\mathrm{i}$-th support vector, and $x_{j}$ represents the input variable of the $j$-th training set. b is the structure coefficient, $\alpha_{i}$ is the support vector coefficient, which is an $n^{*} 1$ determinant, where $n$ is the number of support vectors.

\section{Data}

\subsection{Data source}

We collect city's energy consumption data from the provincial "Statistical Bulletin of Energy Consumption per Unit of GDP and Other Indicators". Other indicators are collected from the China Urban Statistical Yearbook, the China Urban Construction Statistical Yearbook, the China Regional Economic Statistical Yearbook, and the provincial statistical yearbooks.

A total of 292 prefecture-level cities' energy consumption data in 2016 are collected. And 18 indicators including population, GDP, industrial structure, urban population, public transportation, etc. of these 292 prefecture-level cities are also collected.

\subsection{Influencing factors}

By referring the literature, it is noted that factors affecting China's regional energy consumption include industrial structure, economic development level, geographic location, energy price, technology level, energy consumption structure, product structure, export structure, investment, etc.

Using SPSS 19.0 to analyze the correlation of data, we find that in 2016, the GDP per capita, urbanization rate, private car per capita ownership and other 12 indicators are significantly correlated with the energy consumption per capita at $1 \%$ confidence level; and the sewage treatment rate, the real estate development investment per capita completion are significantly correlated with the energy consumption per capita at 5\% confidence level.

Table 1 Correlation and significance of per capita energy consumption and indicators (2016)

\begin{tabular}{ccc}
\hline Indicator & $\begin{array}{c}\text { Pearson } \\
\text { correlation }\end{array}$ & $\begin{array}{c}\text { significance } \\
\text { (bilateral) }\end{array}$ \\
\hline GDP per capita & $0.559^{* *}$ & 0.000 \\
\hline Urbanization rate & $0.483^{* *}$ & 0.000 \\
\hline Private car ownership per capita & $0.455^{* *}$ & 0.000 \\
\hline $\begin{array}{c}\text { Gross industrial output value above } \\
\text { the scale per capita }\end{array}$ & $0.419^{* *}$ & 0.000 \\
\hline Civilian car ownership per capita & $0.407^{* *}$ & 0.000 \\
\hline $\begin{array}{c}\text { Total investment in fixed assets per } \\
\text { capita }\end{array}$ & $0.399^{* *}$ & 0.000 \\
\hline Total retail sales of consumer goods & $0.350^{* *}$ & 0.000 \\
\hline $\begin{array}{c}\text { per capita } \\
\text { The proportion of the second } \\
\text { production }\end{array}$ & $0.319^{* *}$ & 0.000 \\
\hline $\begin{array}{c}\text { Park green area per capita } \\
\text { Heating time }\end{array}$ & $0.300^{* *}$ & 0.000 \\
\hline
\end{tabular}




\begin{tabular}{|c|c|c|}
\hline \multicolumn{3}{|l|}{ per capita } \\
\hline Whether heating & $0.243^{* *}$ & 0.000 \\
\hline Road area per capita & $0.232 * *$ & 0.000 \\
\hline $\begin{array}{l}\text { Urban maintenance and } \\
\text { construction }\end{array}$ & $0.214 * *$ & 0.001 \\
\hline Sewage treatment rate & $0.160^{*}$ & 0.012 \\
\hline $\begin{array}{l}\text { Real estate development investment } \\
\text { completion per capita }\end{array}$ & $0.137^{*}$ & 0.031 \\
\hline Gas penetration rate & 0.118 & 0.064 \\
\hline $\begin{array}{l}\text { Housing construction completion } \\
\text { area per capita } \\
\end{array}$ & 0.116 & 0.069 \\
\hline $\begin{array}{l}\text { Housing construction investment } \\
\text { completion per capita }\end{array}$ & 0.109 & 0.085 \\
\hline Daily water consumption per capita & -0.066 & 0.299 \\
\hline $\begin{array}{l}\text { Urban construction land accounts } \\
\text { for the proportion of urban area }\end{array}$ & 0.039 & 0.541 \\
\hline \multicolumn{3}{|c|}{$\begin{array}{r}\text { Note } \quad * * \text {. Significantly correlated at } 0.01 \text { level (both sides). } \\
* \text {. Significantly correlated at the } 0.05 \text { level (both sides). }\end{array}$} \\
\hline
\end{tabular}

\section{Modeling}

SVM is used to establish a quantitative relationship model between city's energy consumption and influencing factors. The basic logic of this part of the study is to identify the ability of these factors to explain the relationship. The approach is to divide all cities into two groups, one for the training sample and the other for the test sample. Using the training sample data, establish a quantitative relationship model between city's energy consumption and influencing factors, and then apply the established model to the test sample. By constantly adjusting the variables and model structures, the most suitable model is explored.

Variables. The model output variable is the energy consumption per capita. The input variables included in the model including: GDP per capita, heating, urbanization rate, proportion of second industry, number of public transportation vehicles per 10,000 people, gas penetration rate, urban maintenance and construction expenditure per capita, road area per capita, daily water consumption per capita, sewage treatment rate, park green area per capita, bus and trolley bus operation per capita, industrial output value per capita, retail sales per capita, urban construction land to urban area, real estate development investment per capita, fixed assets investment per capita, private car ownership per capita, and the housing area per capita.

Data processing. Data standardization: As the model's output variable, the energy consumption per capita is normalized by minus the mean and divided by the standard deviation. Among the explanatory variables, except for the heating variable which is a "zero-one" variable, other variables are standardized in the same way. Missing value processing: In 2016, the lack of city's energy consumption is substituted by its 2017 energy consumption, and if it is missing in 2017, the sample will be deleted. For the missing explanatory variables in 2016, it is substituted or deleted in the same way. Outlier processing: for those data showing a drastic fluctuation in history will be regarded as an abnormal value.

Training samples and test samples. A total of 249 valid samples were sorted out, in which $80 \%$ were randomly selected as training samples, and the rest were test samples.

Test results. Five random sampling tests were performed by SVM modeling. The prediction effect is expressed by relative error (MAPE), which reflects the percentage of the predicted value deviating from the true value. The five test results were $23.94 \%, 25.65 \%, 23.22 \%$, $26.96 \%$, and $23.4 \%$, respectively. The third sampling modeling test results are shown in Figure 2.:

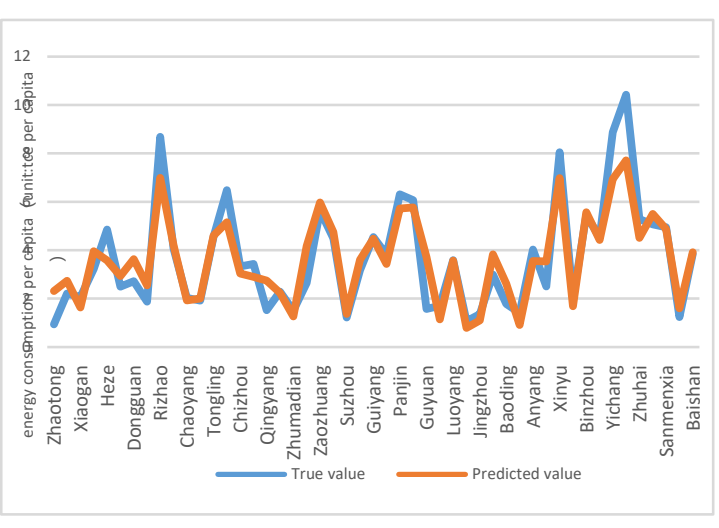

Figure 2 Comparison of predicted and energy consumption per capita

\section{Results}

Applying the model established above, included only the objective uncontrollable factors such as GDP per capita, heating, urbanization rate, proportion of Secondy industry, industrial output value above the scale per capita, and fixed assets investment per capita. The output of the model is the objective energy demand of the city. Classify cities according to the value of this objective energy demand, the results are shown in Table 2.

Table 2 Urban classification based on objective energy demand (unit: tce per capita)

\begin{tabular}{|c|c|c|c|c|}
\hline \multirow{2}{*}{$\begin{array}{l}\text { Category } \\
\text { Number }\end{array}$} & \multirow{2}{*}{ Category Name } & \multicolumn{2}{|c|}{$\begin{array}{l}\text { Objective energy } \\
\text { demand per capita }\end{array}$} & \multirow[b]{2}{*}{$\begin{array}{l}\text { Number } \\
\text { of cities }\end{array}$} \\
\hline & & $\begin{array}{l}\text { Lower } \\
\text { critical }\end{array}$ & $\begin{array}{l}\text { Upper } \\
\text { critical }\end{array}$ & \\
\hline 1 & $\begin{array}{c}\text { Objective energy demand } \\
\text { low level } 6\end{array}$ & & 1.5 & 10 \\
\hline 2 & $\begin{array}{c}\text { Objective energy demand } \\
\text { low level } 5 \\
\end{array}$ & 1.5 & 2 & 36 \\
\hline 3 & $\begin{array}{c}\text { Objective energy demand } \\
\text { low level } 4 \\
\end{array}$ & 2 & 2.5 & 35 \\
\hline 4 & $\begin{array}{c}\text { Objective energy demand } \\
\text { low level } 3\end{array}$ & 2.5 & 3 & 39 \\
\hline
\end{tabular}




\begin{tabular}{|c|c|c|c|c|}
\hline 5 & $\begin{array}{c}\text { Objective energy demand } \\
\text { low level } 2\end{array}$ & 3 & 3.5 & 25 \\
\hline 6 & $\begin{array}{c}\text { Objective energy demand } \\
\text { low level } 1 \\
\end{array}$ & 3.5 & 4 & 26 \\
\hline 7 & $\begin{array}{c}\text { Objective energy demand } \\
\text { average level }\end{array}$ & 4 & 4.5 & 21 \\
\hline 8 & $\begin{array}{c}\text { Objective energy demand } \\
\text { high level } 1\end{array}$ & 4.5 & 5 & 19 \\
\hline 9 & $\begin{array}{c}\text { Objective energy demand } \\
\text { high level } 2\end{array}$ & 5 & 5.5 & 12 \\
\hline 10 & $\begin{array}{c}\text { Objective energy demand } \\
\text { high level } 3 \\
\end{array}$ & 5.5 & 6 & 11 \\
\hline 11 & $\begin{array}{c}\text { Objective energy demand } \\
\text { high level } 4 \\
\end{array}$ & 6 & 6.5 & 6 \\
\hline 12 & $\begin{array}{l}\text { Objective energy demand } \\
\text { high level } 5\end{array}$ & 6.5 & 7 & 5 \\
\hline 13 & $\begin{array}{c}\text { Objective energy demand } \\
\text { high level } 6\end{array}$ & 7 & & 8 \\
\hline
\end{tabular}

Compare the actual energy consumption of the city and the objective energy demand in each category. The bigger the objective energy demand than the city's actual energy consumption, the more prominent the management is in the city, and vice versa. We rank cities based on this gap between the actual energy consumption of the city and the objective energy demand. Figure 3 is such an example of category 8 .

Figure 3 Energy efficiency ranking of sub-categories(unit: tce per capita)

\begin{tabular}{ccccc}
\hline City & $\begin{array}{c}\text { Actual } \\
\text { energy } \\
\text { consumptio } \\
\text { n per capita }\end{array}$ & $\begin{array}{c}\text { Objective } \\
\text { energy } \\
\text { demand } \\
\text { Qer capita }\end{array}$ & $\begin{array}{c}\text { Actual energy } \\
\text { consumption } \\
\text { minus Objective } \\
\text { energy demand } \\
\text { per capita }\end{array}$ & \\
\hline Qingdao & 3.04 & 4.74 & -1.69 & 1 \\
\hline Xi'an & 3.20 & 4.75 & -1.56 & 2 \\
\hline Quanzhou & 4.19 & 4.63 & -0.44 & 3 \\
\hline Zhongshan & 4.30 & 4.61 & -0.31 & 4 \\
\hline Tongchuan & 4.49 & 4.80 & -0.31 & 5 \\
\hline Zhenjiang & 4.50 & 4.81 & -0.31 & 6 \\
\hline Xiamen & 4.70 & 4.88 & -0.19 & 7 \\
\hline Tongling & 4.55 & 4.69 & -0.14 & 8 \\
\hline Shanghai & 4.84 & 4.65 & 0.19 & 9 \\
\hline Jiaozuo & 4.85 & 4.61 & 0.24 & 10 \\
\hline Hulunbeier & 5.07 & 4.76 & 0.31 & 11 \\
\hline Hohhot & 4.99 & 4.68 & 0.31 & 12 \\
\hline Sanmenxia & 4.95 & 4.62 & 0.32 & 13 \\
\hline Zaozhuang & 5.64 & 4.63 & 1.01 & 14 \\
\hline Tongliao & 6.08 & 4.97 & 1.11 & 15 \\
\hline & & & &
\end{tabular}

\begin{tabular}{ccccc}
\hline Lanzhou & 6.35 & 4.93 & 1.43 & 16 \\
\hline Jincheng & 6.31 & 4.63 & 1.68 & 17 \\
\hline Maanshan & 8.48 & 4.55 & 3.93 & 18 \\
\hline Rizhao & 8.68 & 4.63 & 4.05 & 19 \\
\hline
\end{tabular}

\section{Case study}

We choose Qingdao, ranking first in the No. 8 category, as our model city to do our case study as follows. In 2005, the total energy consumption of Qingdao was 25.88 million tons of standard coal, and the energy consumption per capita was 3.19 tons of standard coal. In 2017, the total energy consumption was 32.89 million tons of standard coal, and the energy consumption per capita was 3.54 tons of standard coal. In 12 years, the total energy consumption has increased by $27 \%$, with an average annual growth rate of $2 \%$; energy consumption per capita has increased by $11 \%$, with an average annual growth rate of $0.9 \%$.

\subsection{Qingdao's category}

Qingdao is located in Shandong Province. It is a subprovincial city. In 2016, Qingdao's GDP per capita was 108,771 yuan, which was 1.93 standard deviations above the national average. The urbanization rate is $32 \%$, which is 0.69 standard deviations above the national average. The total industrial output value per capita above the scale is 177,573 yuan, which is 1.44 standard deviations above the national average. The social fixed assets investment per capita was 42,568 yuan, which was 1.26 standard deviations above the national average. Considering all these factors, the demand for energy consumption is objectively higher in Qingdao. According to the model established in this study, the objective energy demand per capita in Qingdao is 4.68 tons of standard coal, which falls to the category of 18 , with other 17 cities including Xi'an, Quanzhou, Zhongshan and Xiamen, etc.

\subsection{Energy efficiency assessment}

Compared with the objective energy demand of 4.68 tons of standard coal per capita, Qingdao's actual energy consumption is 3.04 tons of standard coal per capita, which is much lower, suggesting that the city's performance in energy efficiency is better than national average. In fact, Qingdao ranks first in its category.

In 2016, the number of public transportation vehicles per 10,000 people in Qingdao was 19.02, which was 1.33 standard deviations above the national average. The gas penetration rate was $100 \%$, which was 0.59 standard deviations above the national average. The sewage treatment rate was $96.08 \%$, which was 0.50 standard deviation higher than the national average. The park green area per capita was 18.55 square meters, which is 0.91 standard deviation higher than the national average. Buses and trolleybuses operated per capit was 7.83 vehicles, which was 1.66 standard deviations above the national average. The housing construction area per capita was 2.30 square meters, which was 0.03 standard deviation 
lower than the national average. The above data shows that Qingdao is significantly better than the national average in terms of public transportation, green space construction, sewage treatment, etc. The development of these aspects is conducive to Qingdao to maintain a low energy consumption level.

Although the overall performance is outstanding, Qingdao has room to improve. In 2016, the number of private cars per capita was 0.14 , which was 1.42 standard deviations above the national average. The total retail sales of consumer goods per capita was 44,599.46 yuan, which was 2.10 standard deviations higher than the national average. The results of these data show that due to the high income level, Qingdao residents' demand for automobiles and consumer goods is relatively strong. While stimulating economic growth, it also potentially increases the demand for energy.

\subsection{Future plan}

According to the assessment results, Qingdao's energy efficiency level is in the forefront, and its further optimization is mainly in terms of transportation and residential consumption. According to the "Qingdao Energy Conservation and Green Development Action Plan (2018-2020)", Qingdao will save energy in the fields of industrial, building, transportation, public institution, etc.

The first step is to strengthen industrial energy conservation. Government needs to promote the clean utilization of coal and the efficient use of new energy. To carry out energy measurement review activities for key energy-using units. The second step is to strengthen building energy efficiency. To implement the standard of $75 \%$ energy efficiency for residential buildings and $65 \%$ energy efficiency for public buildings, and develop energy-efficient buildings. The third step is to promote energy conservation in transportation. To develop public transportation, especially the medium and low-traffic public transport such as modern trams. Promote energysaving and environment friendly vehicles, such as $\mathrm{CNG} / \mathrm{LNG}$ powered vehicles. The fourth step is to strengthen energy conservation in public institutions. To eliminate old vehicles that meet the conditions for scrapping, take the lead in using new energy vehicles, and gradually increase the proportion of new energy vehicles according to regulations. To explore new ways for public institutions to adopt energy management and energy conservation technology.

\section{Conclusion}

City's energy efficiency assessment based on classification is to improve the comparability and accuracy of energy efficiency assessment between cities, thus improve the scientific and targeted management of energy conservation.

Firstly, city's energy efficiency assessments can promote the diffusion of energy conservation experiences. Energy management is an integral part of public management. China has a vast territory with 292 prefecture-level cities, and has rich experience in energysaving management. Thus, we can identify the best practices of energy conservation management. Local governments can calculate the gap between energy intensity in their own region and advanced regions, and identify key areas for energy conservation.

Secondly, city's energy efficiency assessment is aimed to achieve a fair assessment considering the objective difference between cities. There are many cities in China, which have quite different geographical location, industrial structure, resource endowment, and economic development level. These factors have significant impact on city's energy efficiency, and are hard to change by our effort. In this study, we eliminate the impact of these objective factors by categorizing cities, which prove to be a better way to improve the accuracy of energy efficiency assessment.

Thirdly, energy efficiency assessments can promote energy saving at marginal costs. Based on the results of city classification, energy efficiency assessment, and systematic analysis on best practice of model cities, we identify the cities and areas with the greatest potential for energy savings. For cities with the greatest potential should be given more attention and investment to. For the whole society, energy saving action that meets the marginal cost can achieve energy saving goals with minimal cost.

Finally, energy efficiency assessments are needed to better promote information disclosure and sharing. Information disclosure and sharing are the first step in research and basic work of energy revolution. There are many ways to promote information disclosure and sharing, such as through legislation and so on. Objectively, energy efficiency assessment is conducive to promoting information disclosure. The city government can effectively introduces the public supervision mechanism through the city's energy efficiency assessment system. In the future, our research will focus on all the information, data and cases involved in city's energy efficiency management, and aggregate the information into the platform database to facilitate public inquiry, realizing the integration and disclosure of energy-related statistical information, and ultimately promote the development of the city's transforming to an more energy-efficient society

\section{Acknowledgement}

The collection of data in this paper were completed with the support of Beijing EnDigishare Environmental Techniques Research Institute (http://www.3edata.com). We would like to express sincere thanks to them. 


\section{References}

1. World Energy Council (WEC). New renewable energy resources: a guide to the future[M].1994.

2. Shi Dan. Analysis of Regional Differences and Energy Saving Potentials of Energy Efficiency in China[J]. China Industrial Economy, 2006(10): 4958.

3. Yang Hongliang,Shi Dan,Xiao Jie.The Influence of Natural Environment Factors on Energy Efficiency-Analysis of Theoretical Energy Saving Potential and Actual Energy Saving Potential in Different Regions of China[J].China Industrial Economy,2009(4):73-84.

4. SHI Dan, WU Lixue, FU Xiaoxia, WU Bin. Research on Regional Differences of Energy Efficiency in China and Its Causes-Partition Decomposition Based on Stochastic Frontier Production Function[J]. Management World, 2008(2): 35-43.

5. Liu Manzhi, Liu Xianxian. Analysis of the Factors Affecting the Energy Consumption of Urban Residents in China and Their Effects_-Based on the Static Panel Data Model of Eight Regions[J]. Resources Science, 2016(12):2295-2306

6. Liu Manzhi, Liu Xianxian, Chen Meng. Energy Consumption in Urban Life in China: Analysis of Influencing Factors and Spatial Differences[J]. Journal of Capital University of Economics and Business, 2017, 19(5): 13-20.

7. Hao Y, Peng H. On the convergence in China's provincial per capita energy consumption: New evidence from a spatial econometric analysis[J]. Energy Economics, 2017, 68:31-43

8. Song Guojun, Ma Ben. Research on Urban Energy Efficiency Assessment in China[M]. Chemical Industry Press, 2013.

9. Song Guojun, Guo Xiaodan. Classification and assessment of direct energy consumption in urban life. China Population, Resources and Environment. 2018(6): 1-10.

10. Song Guojun, Guo Xiaodan, Fang Guobin. Urban comprehensive energy consumption per capita assessment research. Environmental pollution and prevention. 2019(1): 124-128. 